\title{
Psychotropic prescriptions for the treatment of schizophrenia in an outpatient clinic
}

\author{
Prescrições psicotrópicas para o tratamento da esquizofrenia em \\ uma clínica ambulatorial
}

\author{
Christopher Izehinosen Okpataku, ${ }^{1}$ David Tawani ${ }^{2}$
}

\begin{abstract}
Introduction: There is an unpredictable pattern in the prescription of antipsychotics and other psychotropic medications for the treatment of schizophrenia, particularly in resourcelimited settings in developing countries.

Objective: To determine the psychotropic prescriptions given to patients with schizophrenia in an outpatient clinic of a tertiary hospital and to describe the choices and trends of these prescriptions.

Methods: This was a cross-sectional descriptive study of prescriptions for adults with schizophrenia. After clinical consultation, patients' case notes were randomly selected over a period of 2 years. Using a structured form, data were extracted from the case notes including biodemographic data, psychotropic medications prescribed and changes made to these prescriptions. Data were analyzed by means of descriptive statistics.

Results: A total of 103 patients were selected, with a mean age of $35.96 \pm 9.78$ years; $48.5 \%$ were males and $51.5 \%$ were females; $33 \%$ were unemployed and $38 \%$ had been hospitalized in the past. There were 231 initial prescriptions and 228 current prescriptions, with about 2.2 prescriptions per patient. Haloperidol (mean dose $14.77 \pm 6.28 \mathrm{mg}$ and $11.44 \pm 5.55 \mathrm{mg}$ for initial and current) and other old-generation antipsychotics were the most commonly prescribed for new cases (98\%). Mean duration of psychotropic use was $7.78 \pm 5.6$ years. All the patients were prescribed trihexyphenidyl, and $56.3 \%$ of the patients had their medications changed as a result of side effects.

Conclusion: There was a very high preference for the use of first-generation antipsychotics for all treatment settings (in- and outpatients), a pattern that is likely to persist.
\end{abstract}

Keywords: Psychotropic, prescription, schizophrenia, clinic.

\section{Resumo}

Introdução: Existe um padrão imprevisível na prescrição de antipsicóticos e outros medicamentos psicotrópicos para o tratamento da esquizofrenia, especialmente em ambientes com limitação de recursos em países em desenvolvimento.

Objetivo: Determinar as prescrições psicotrópicas dadas a pacientes com esquizofrenia em uma clínica ambulatorial de um hospital terciário e descrever as escolhas e tendências dessas prescrições.

Métodos: Este foi um estudo descritivo transversal das prescrições dadas a adultos com esquizofrenia. Após consulta clínica, os prontuários dos pacientes foram selecionados aleatoriamente ao longo de um período de 2 anos. Usando um formulário estruturado, os dados foram extraídos dos prontuários, incluindo dados biodemográficos, medicamentos psicotrópicos prescritos e mudanças feitas a essas prescrições. Os dados foram analisados por meio de estatística descritiva.

Resultados: Um total de 103 pacientes foram selecionados, com idade média de $35,96 \pm 9,78$ anos; $48,5 \%$ eram do sexo masculino e $51,5 \%$ do sexo feminino; $33 \%$ estavam desempregados e $38 \%$ haviam sido hospitalizados no passado. Houve 231 prescrições iniciais e 228 prescrições atuais, com aproximadamente 2,2 prescrições por paciente. O haloperidol (dose média de $14,77 \pm 6,28 \mathrm{mg}$ e $11,44 \pm 5,55 \mathrm{mg}$ para prescrições inicial e atual) e outros antipsicóticos de primeira geração foram os mais comumente prescritos para casos novos (98\%). A duração média do uso de psicotrópicos foi de $7,78 \pm 5,6$ anos. Todos os pacientes receberam prescrição de triexifenidil, e $56,3 \%$ dos pacientes tiveram seus medicamentos alterados como resultado de efeitos colaterais.

Conclusão: Houve uma alta preferência pelo uso de antipsicóticos de primeira geração para todos os regimes de tratamento (internação e ambulatorial), um padrão que provavelmente persistirá.

Descritores: Psicotrópico, prescrição, esquizofrenia, clínica.

\footnotetext{
${ }^{1}$ Department of Psychiatry, College of Health Sciences, Bingham University, Jos, Nigeria. ${ }^{2}$ Department of Psychiatry, Ahmadu Bello University Teaching Hospital, Zaria, Nigeria.

Submitted Dec 23 2016, accepted for publication Apr 122017.

Suggested citation: Okpataku CI, Tawani D. Psychotropic prescriptions for the treatment of schizophrenia in an outpatient clinic. Trends Psychiatry Psychother. 2017;39(3):165-172. Epub 31 Aug 2017. http://dx.doi.org/10.1590/2237-6089-2016-0088
} 


\section{Introduction}

Schizophrenia is one of the most disabling and economically catastrophic disorders. According to the World Health Organization, it is one of the top ten illness contributing to the global burden of disease. ${ }^{1}$ It is a chronic and debilitating condition where prompt and effective management is crucial in determining and mitigating the diverse and potentially profound consequences of the disorder.

Pharmacotherapy has been the primary treatment for schizophrenia, and antipsychotics are the first-line drugs used. They have been shown in clinical trials to be effective in treating symptoms and behaviors associated with the disorder. ${ }^{2,3}$ The introduction of chlorpromazine in the mid-20th century ${ }^{4,5}$ for the treatment of psychosis was a landmark in the management of schizophrenia and other related psychoses. Today, first-generation (FGA) and second-generation antipsychotics (SGA) are the groups of psychotropics used to treat schizophrenia. ${ }^{6,7}$

An unpredictable pattern has been observed in the prescription of antipsychotics and other psychotropic medications to patients with schizophrenia in clinical practice. In some parts of the world, there is a higher percentage of prescriptions of SGAs, ${ }^{8-10}$ while in others, FGAs are preferably prescribed. ${ }^{10-12}$ In Nigeria, oldgeneration antipsychotics were reported as the most commonly prescribed medications for the treatment of schizophrenia, both decades ago ${ }^{13}$ and recently. ${ }^{14}$ FGAs were also mostly used for the treatment of other psychotic disorders, ${ }^{15}$ but olanzapine, an SGA, was found to be the most frequently prescribed antipsychotic in monotherapy in a recent study. ${ }^{16}$ Antiparkinsonian drugs were often prescribed at the onset of treatment, ${ }^{17}$ against side effects, without evidence that the latter would occur in the course of treatment.

The choice of antipsychotics prescribed to a patient with schizophrenia has a significant relationship with the long-term outcome of the disorder. ${ }^{18,19}$ In this sense, it is extremely important to evaluate how accumulating knowledge and the emerging use of SGAs in some parts of the world influence prescriptions for schizophrenia in clinical practice over time in our setting. We speculate that in a teaching hospital, where future psychiatrists are trained, the pattern of prescriptions established for patients will ultimately influence the choices of medications that these physicians will prescribe post-training.

Therefore, this study sought to determine the psychotropic prescriptions given to patients with schizophrenia at the outpatient clinic of a tertiary teaching hospital in Nigeria. It describes choices and trends, and how they relate to other factors that may influence treatment outcomes.

\section{Materials and methods}

This was a retrospective (patient chart-based), descriptive, cross-sectional study carried out over a 2-year period in the Zaria Federal Teaching Hospital, a major tertiary service center in North West Nigeria that has been providing medical services to Zaria plus at least nine other neighboring states and other parts of the country. The study was conducted in the psychiatric outpatient clinic of the hospital. The clinic is run by psychiatrists and resident (trainee) psychiatrists. There were three psychiatrists and 18 residents running the clinic at the time of the study. All patients diagnosed with schizophrenia who had been attending the clinic for at least the preceding 12 months were considered eligible for inclusion in the study.

After consulting their physicians during the routine monthly psychiatric clinical visits at the outpatient department, the case records of eligible patients were identified and retrieved.

An average of six case notes were randomly selected from the physicians who saw patients at the psychiatry clinic over the period lasting from May 2014 to April 2016. The hospital's clinic visits are held twice a week. On each clinic visit day, the first three patients to consult the first three psychiatrists to arrive at the clinic were selected. At the next visit day, the last three patients who consulted the last three physicians to arrive at the clinic were selected. Case notes were assigned a number and marked to prevent repetition of data extraction. Although all the data originated from the outpatient clinic, patients were grouped into hospitalized vs. non-hospitalized patients. All hospitalized patients were moved to the outpatient clinic after discharge from inpatient care. The outpatient clinic therefore consists of never-hospitalized clinical attendees (non-hospitalized patients) and those who have been discharged from in-patient care (hospitalized patients). Data were not collected for 2 months during the study period as a result of industrial strike action at the hospital, which interrupted hospital services.

Using a structured form, information on the patients' basic biodemographic data, diagnosis, duration of illness and psychotropic use, initial and current medications, and changes in medications were recorded. Initial medication was defined as the first drug prescribed to the patient during his/her first contact with a psychiatrist. Current medication was defined as the drug that the patient had been receiving up to the time of data extraction from his/her case notes. Inquiries as to the availability of treatment guidelines and how physicians adhered to these guidelines were also made.

Ethical clearance for the study was given by the Health Research Ethics Committee of the Ahmadu Bello 
University Teaching Hospital. The data obtained were entered and analyzed by means of descriptive statistics using the Statistical Package for the Social Sciences (SPSS) for Windows version 20.

\section{Results}

A total of 103 patients with schizophrenia were selected, of which $48.5 \%$ were male, and $51.5 \%$ female. Mean age of the patients was 35.96 $19.78 ; 32 \%$ of them were employed, while $68 \%$ were not gainfully employed. Also, 38\% (39) were hospitalized in the past, while $62 \%$ (64) were not (Table 1 ).

There was a total of 234 initial prescriptions and 228 current prescriptions, with an average of 2.2 prescriptions per patient, consisting of two antipsychotics and an anticholinergic agent. All patients received trihexyphenidyl tablets. All the medications were taken orally (tablets), with the exception of fluphenazine and flupentixol, which were administered via parenteral route (injection).

Haloperidol was the most commonly prescribed drug to patients who had been admitted to hospital in the past (67.9\%). Other FGAs $(28.3 \%)$ were mostly prescribed for these groups of patients, rather than SGAs (3.8\%) (Figure 1).

Haloperidol (35.8\%) and other FGAs (39.6\%) were also the most commonly prescribed current medications to patients who had been admitted in the past, but there was an increase in the proportion of those who received SGAs $(24.5 \%)$ (Figure 2 ).

Similarly, haloperidol (52\%) and other FGAs (46\%) were the most commonly prescribed initial drugs for the treatment of schizophrenia in non-hospitalized patients at their first presentation at the outpatient clinic, upon initiation of treatment (Figure 3).

Haloperidol (30\%) and other FGAs (50\%) were the most commonly prescribed medications for the continuation of

Table 1 - Sociodemographic characteristics of the patients

\begin{tabular}{lcc}
\hline Variable & Frequency & Percentage \\
\hline Age (years) & 3 & \\
$>20$ & 64 & 2.9 \\
$20-39$ & 35 & 62.1 \\
$40-59$ & 1 & 34.0 \\
$\geq 60$ & & 1.0 \\
Sex & 50 & \\
$\quad$ Male & 53 & 48.5 \\
Female & & 51.5 \\
Employment status & 33 & \\
Employed & 70 & 32.0 \\
Unemployed & & 68.0 \\
\hline
\end{tabular}

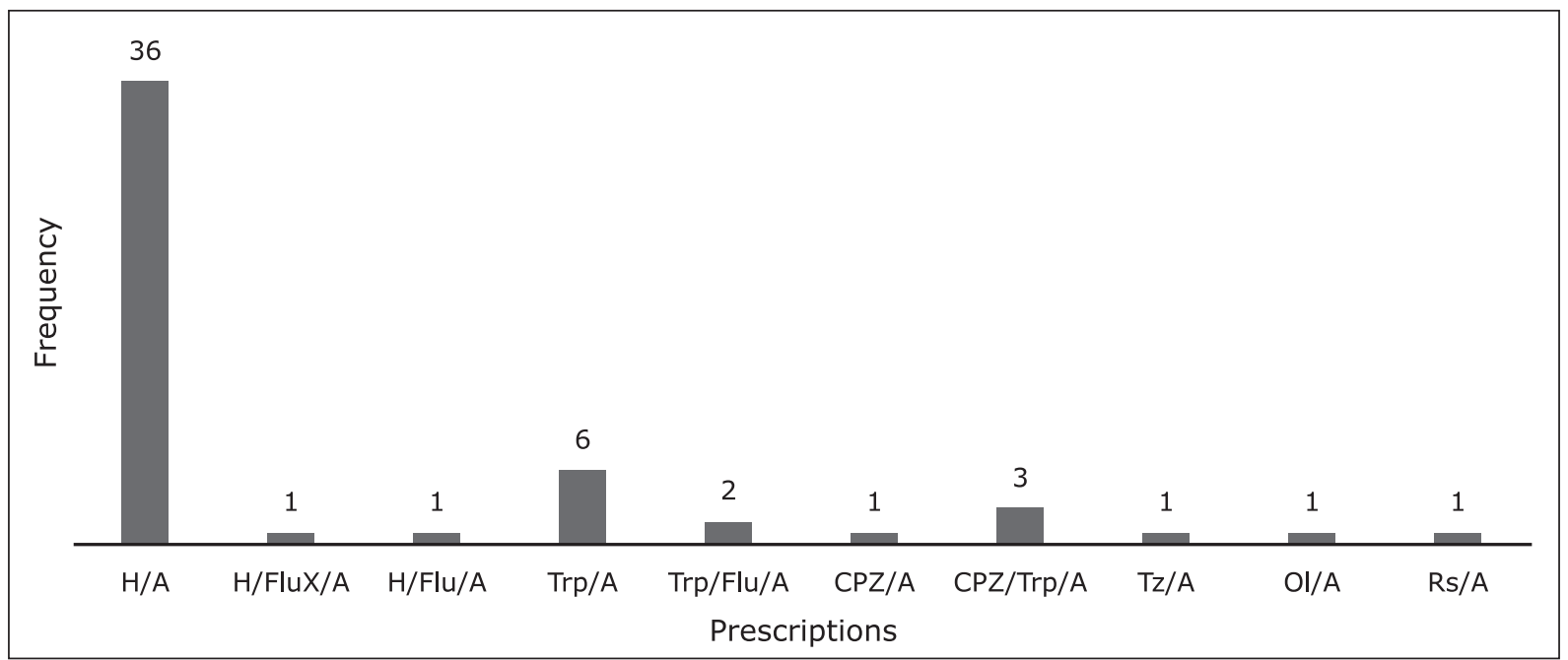

Figure 1 - Initial psychotropics prescribed at first hospitalization. $\mathrm{H}=$ haloperidol; FluX = flupentixol; Flu = fluphenazine; Trp = trifluoperazine; $\mathrm{CPZ}=$ chlorpromazine; $\mathrm{Tz}=$ thioridazine; $\mathrm{Ol}=$ olanzapine; $\mathrm{Rs}=$ risperidone; $\mathrm{A}=$ artane. 
treatment in outpatients who had never been hospitalized. SGAs were prescribed to a few patients (18\%) (Figure 4).

Upon treatment initiation, considering both hospitalized and non-hospitalized patients, 98-99\% of the antipsychotics used were FGAs. For treatment continuation, about $10.6-12.6 \%$ of the prescriptions were changed to SGAs (olanzapine and risperidone).

Mean duration of psychotropic use was 7.78 \pm 5.6 years. Mean dose per day of the most commonly prescribed medication upon treatment initiation was $14.77 \pm 6.28 \mathrm{mg}$ of haloperidol, compared to
$11.44 \pm 5.55 \mathrm{mg}$ haloperidol for current medications used for treatment continuation.

After the initial psychotropics prescribed, changes were made to the prescriptions over time. About 56.3\% of the patients had their medications changed at least once since the beginning of treatment. The reasons for changing the medication were not documented in 33\% of the patients. For those who had a note indicating why their drug type or class was changed, the main reasons included the presence of extrapyramidal side effects $(51.3 \%)$. Other reasons were also given (Figure 5 ).

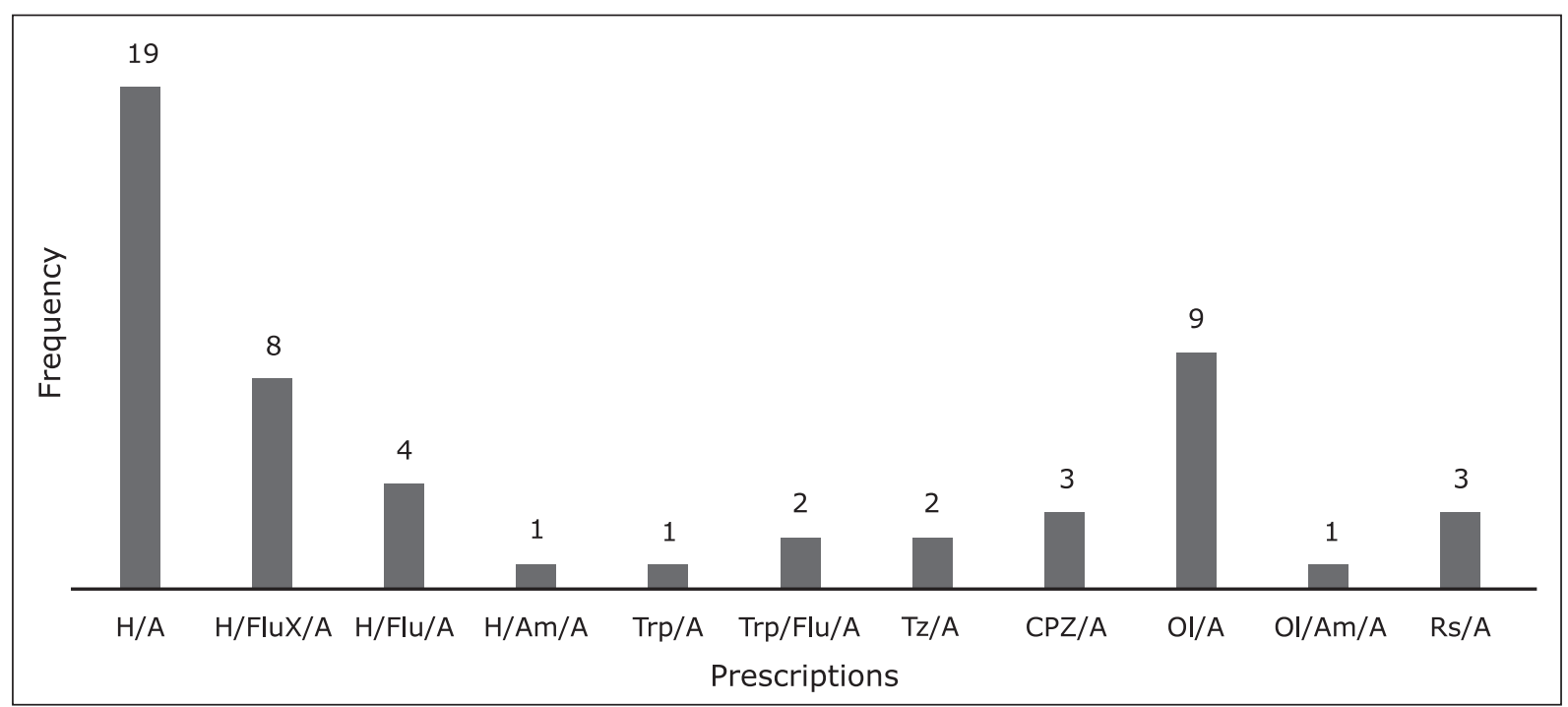

Figure 2 - Current psychotropics prescribed to patients attending the outpatient clinic who had been hospitalized in the past. $\mathrm{H}=$ haloperidol; FluX = flupentixol; Flu = fluphenazine; $\operatorname{Trp}=$ trifluoperazine; $\mathrm{CPZ}=$ chlorpromazine; $\mathrm{Tz}=$ thioridazine; OI = olanzapine; Rs = risperidone; $\mathrm{A}=$ artane.

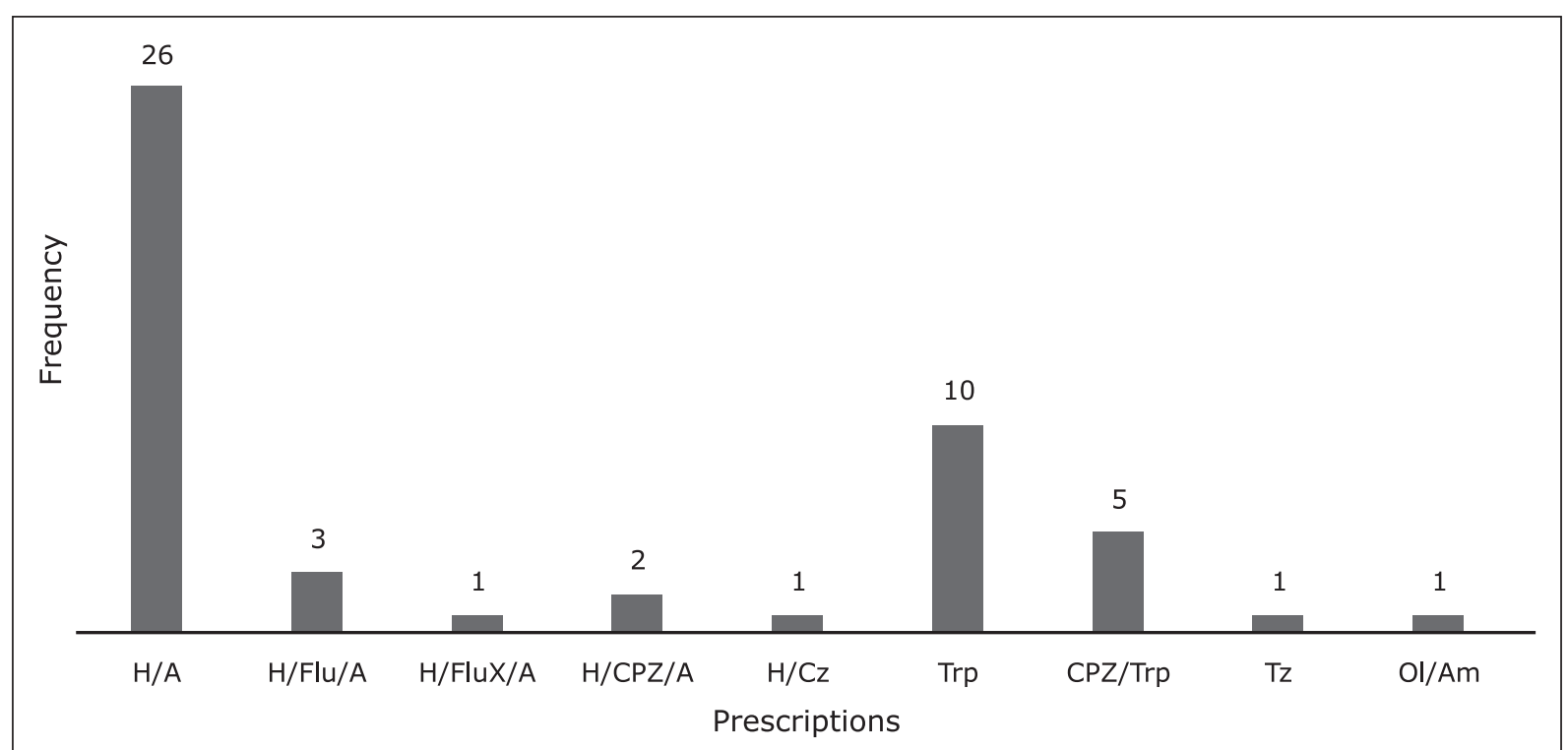

Figure 3 - Initial psychotropics prescribed to outpatients who had never been hospitalized. $\mathrm{H}=$ haloperidol; FluX = flupentixol; $\mathrm{Flu}=$ fluphenazine; $\mathrm{Trp}=$ trifluoperazine; $\mathrm{CPZ}=$ chlorpromazine; $\mathrm{Tz}=$ thioridazine; OI = olanzapine; $\mathrm{Cz}=$ carbamazepine. 
Over the preceding 12 months, 73\% of the patients had no drug-related complaints documented in their case notes. About $27 \%$ indicated complaints such as generalized body weakness, forgetfulness, excessive salivation, excessive sleep and tremors.

At the point of case note examination, $43.7 \%$ of the patients on medication were judged to be "clinically stable" as indicated by "doing well; no complaints today" recorded in their last clinical notes. Conversely, $44.7 \%$ were considered "clinically unstable" as noted by minor complaints such as occasional poor sleep, fleeting irritability and some oddities of behavior, indicating the presence of complaints, worrying or unresolved symptoms. About $11.6 \%$ were considered to be significantly sick, with prominent psychotic symptoms documented in their notes. There were no treatment guidelines (formal or informal) available for the management of schizophrenia.

\section{Discussion}

The choice and pattern of psychotropic utilization in patients with schizophrenia is essential to the understanding and determination of those crucial factors in drug treatment that mitigate or aggravate patients' suffering and positively or negatively affect the outcome of the disease. This may partly account for the ongoing effort from several studies to document and describe the prescriptions and use of antipsychotics and other related medications in patients who are receiving drug treatment for schizophrenia.

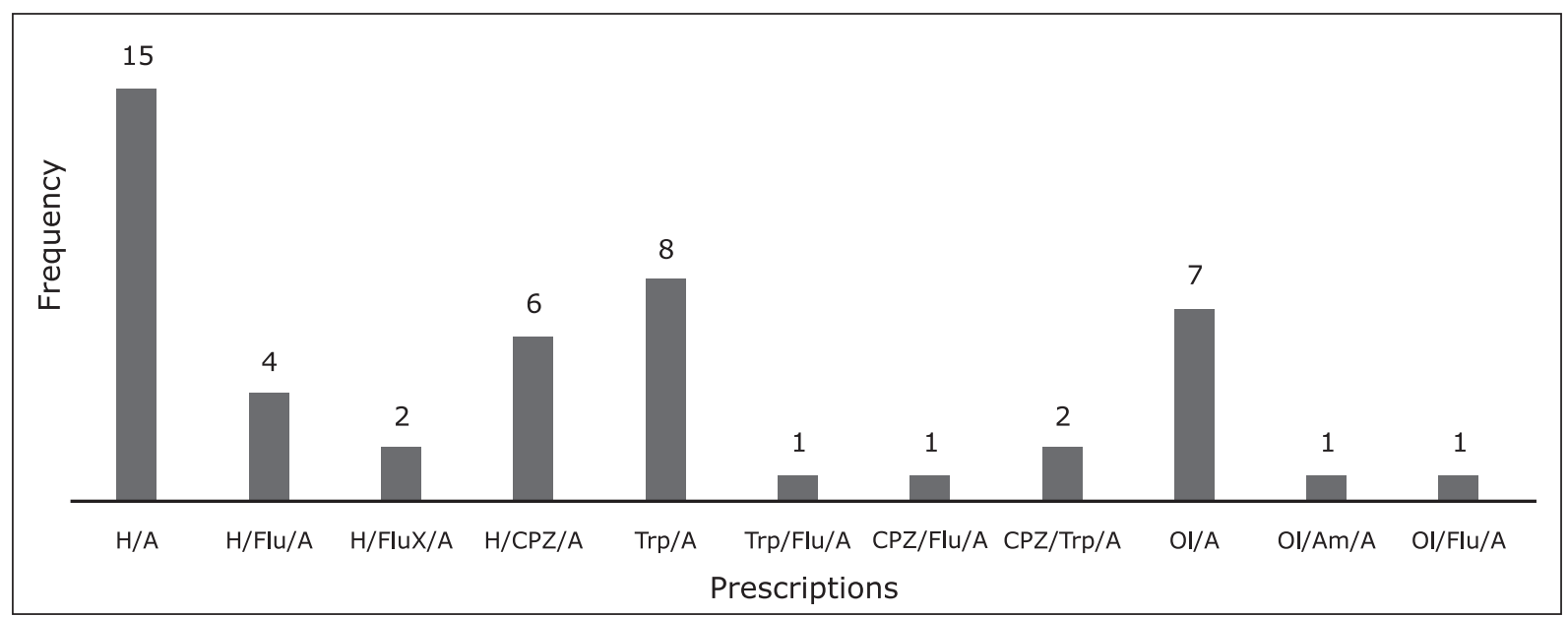

Figure 4 - Current psychotropics prescribed to patients who had never been hospitalized. $\mathrm{H}$ = haloperidol; FluX = flupentixol; Flu = fluphenazine; $\operatorname{Trp}=$ trifluoperazine; $\mathrm{CPZ}=$ chlorpromazine; $\mathrm{Tz}=$ thioridazine; OI = olanzapine; $\mathrm{Rs}=$ risperidone; $\mathrm{A}=$ artane.

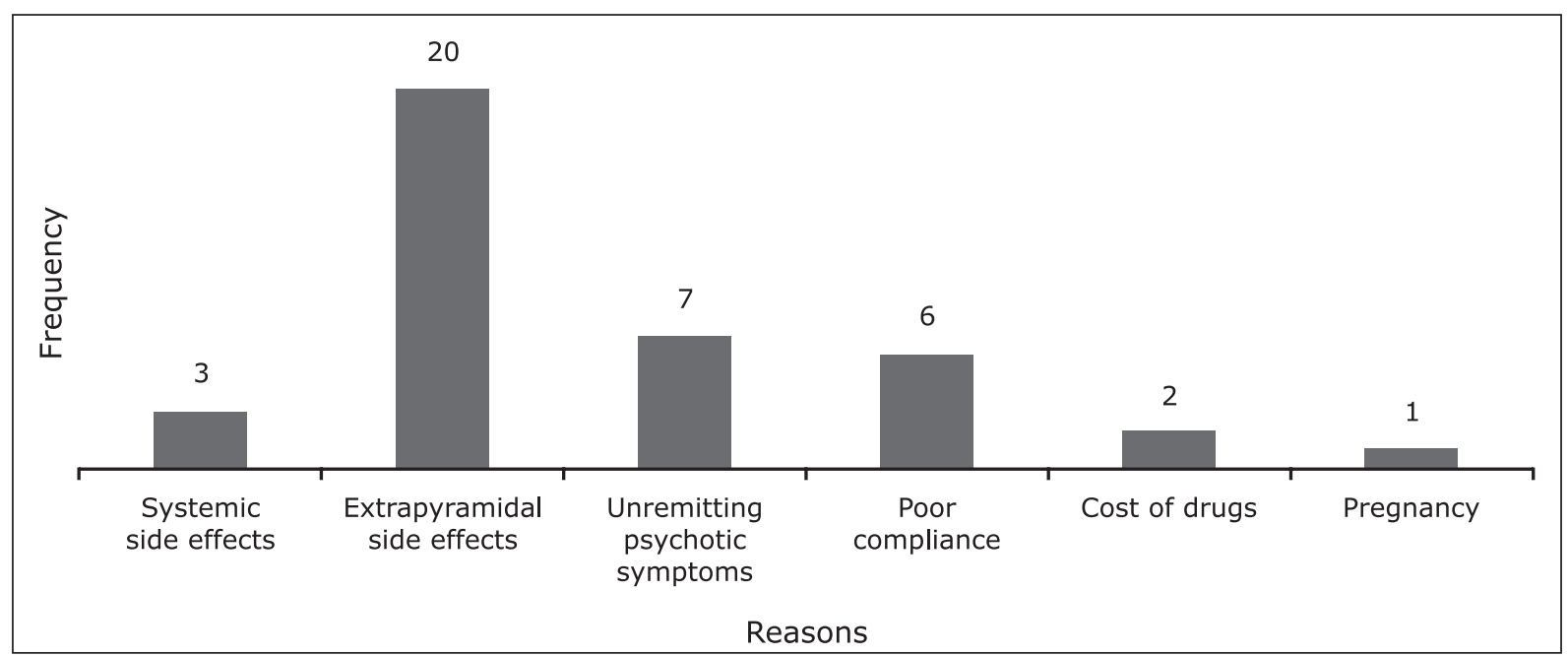

Figure $\mathbf{5}$ - Reasons documented for changing psychotropic prescriptions. 
The age and sex of the respondents in this study were comparable to those reported by similar studies. $8,9,20,21$

About $70 \%$ of the patients were unemployed in this study. Some studies that determined the employment status of patients with schizophrenia who were on antipsychotics found that the majority of them were

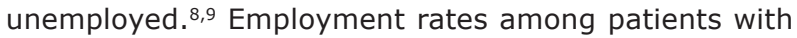
schizophrenia are low, with an estimate from a European study ranging from 8 to $35 \% .{ }^{22}$ Individual factors (such as job histories), illness-related factors (such as illness severity) and societal conditions (such as discrimination and social welfare policy) are all potential contributors to variations in employment rates. ${ }^{23}$

Haloperidol, an FGA, was found to be the most commonly prescribed medication across all categories, while olanzapine was the preferred SGA. The choice of which drug to prescribe is generally influenced by several factors, such as cost of the drug, side effects, actual or perceived efficacy, familiarity with the drug and "new" versus "old" drug. Studies have documented several factors that directly or indirectly influence prescribers, including issues of safety, patient's socioeconomic status, efficacy, formulary status, patients' acceptability/tolerability, clinical symptoms and prescription restrictions. ${ }^{12,24,25}$

The efficacy of FGAs in reducing positive symptoms is not in doubt, 26,27 but their action is quite limited in other outcomes, ${ }^{28}$ notably, their effect on negative symptoms. The side effects of haloperidol and other FGAs constitutes a major problem in the pharmacotherapy of schizophrenia. ${ }^{29}$ This has largely contributed to the search and emergence of SGAs - over the years, these drugs have been increasingly preferred over FGAs. In clinical practice, there has been a growing pattern of prescription of SGAs to patients with schizophrenia. ${ }^{30}$ It was first believed that they were far superior to FGAs. However, that optimism was short-lived, as new findings suggest that SGAs may not have clear superior efficacy or better tolerability compared with FGAs.6,31-33 Still, SGAs have been more favorably explored and utilized in recent times than FGAs. Lewis et al. have suggested that FGAs, which are substantially cheaper, still have a place in the treatment of patients unresponsive or intolerant to the newer medications. ${ }^{33}$ In addition, another report has noted that there is no clear evidence that SGAs are more effective or better tolerated than FGAs. ${ }^{34}$ Those authors concluded that FGAs should be used in the initial treatment of an episode of schizophrenia, unless the patient has not previously responded to these drugs or has unacceptable extrapyramidal side effects. ${ }^{34}$

In developing countries such as Nigeria, or in resource-scarce settings, there is likely going to be an increasing use of FGAs and a slow transition to SGAs, largely as a result of the relatively higher cost of SGAs. These drugs are often not within the reach of patients in our setting in a sustainable manner. The socioeconomic status of patients influences clinical management decisions. ${ }^{35}$ Physicians may have considered affordability over and above other important clinical factors while choosing medications in our study. This may likely be a major reason why our clinic patient population is mainly treated with haloperidol (a relatively cheaper drug), at both initiation and continuation. Although our study did not specifically determine the socioeconomic status of patients, most of them were unemployed. In this regard, we are aware that just as the employment of a patient does not attest to their capability to afford medications, there are unemployed patients who get adequate family and other caregivers support for their treatment. There is also perhaps the effect of trainer-trainee influence on prescription choices that occurs at a teaching hospital setting. Trainee physicians' prescription choices, among other factors, are also likely to be influenced by the pattern established by their supervising physicians. From empirical evidence, trainee physicians tend to "follow" the prescription pattern and choices of their trainers. Therefore, what was observed in this study is likely to have been partly determined by these factors. It is important to note, however, that prescription choices are determined by a complex interaction of multiple factors, considerations and circumstances.

Changes in psychotropic prescriptions in this study were usually from an FGA to an SGA, because the former was often the first drug prescribed to most of the patients. Cost does not seem to have been an important reason for change of medication, as the physicians generally prescribed the cheaper types based on their understanding of the prevailing socioeconomic status of their patients.

Side effects were a major problem associated with the use of FGAs. ${ }^{36}$ This was the major reason for change of the type of drug prescribed in this study. There was an apparent preference for the use of SGAs in clinical situations where FGA-related intolerable side effects were present. Side effects themselves may cause or worsen schizophrenia symptoms, including negative, positive and cognitive symptoms. ${ }^{37}$ In addition, they may increase the risk for other medical disorders ${ }^{38}$ and can affect the patients' quality of life and willingness to take the medication. ${ }^{36,39}$ Whether SGAs have fewer and more tolerable side effects than FGAs is still contentious. Studies have reported that there are no significant differences between SGAs and perphenazine, a representative FGA. ${ }^{32,40}$

Following recent advances on what is known about both classes of antipsychotics, the role of SGAs in the 
management of schizophrenia is a pressing clinical uncertainty. ${ }^{34}$ Most patients with schizophrenia are currently receiving SGAs, particularly olanzapine, as the primary treatment. There has been a growing pattern in their use, ${ }^{30}$ even for off-label purposes, ${ }^{41}$ supported by research evidence, ${ }^{42}$ national policies and marketing campaigns. ${ }^{43}$ There are also treatment guidelines in some countries which recommend SGAs over FGAs. ${ }^{9,44}$ To what extent SGAs have a clear advantage over FGAs is still a subject of debate.

It is interesting to note that no prescription of clozapine was found in this study. At present, clozapine, an SGA, is reserved for the management of difficult-to treat schizophrenia. This may be a conservative approach by physicians to avoid the plethora of adverse effects and routine investigations associated with the use of that drug, or may result from the fact that patients clearly cannot afford the drug. Of note, also, is the record that all patients were on anticholinergic drugs, apparently to treat or prevent some side effects of antipsychotics. This included patients who were admitted to hospital, i.e., who could be watched and managed for such side effects if and when they occurred. Certainly not all patients require this additional pill burden, which is often given perpetually. This practice of prescribing anticholinergics to all patients on antipsychotics may be regarded as polypharmacy.

\section{Limitations}

This study relied on data recorded on patient charts. Additional interviews with the physicians and patients to inquire about their perspectives on prescription choices and treatment outcomes, respectively, would have enriched the quality of results. Secondly, the study was conducted at one center only, so the findings may not be applicable to other tertiary psychiatric facilities.

\section{Conclusion}

The prescription and use of safe, affordable and available antipsychotics in patients with schizophrenia will continue to be a major factor in determining the outcome of the disorder. While there are treatment guidelines to follow in some countries, no recommendations are available in others - including Nigeria. If this study is a modest reflection of the practice of clinics operating in other socioeconomically comparable nations, we do not see predictable changes in the pattern of psychotropic prescriptions to patients with schizophrenia occurring soon. Therefore, it is likely that the decisions on what medications prescribers give to these patients will continue to be highly determined by the individual physicians' experience, personal choices and whatever factors he/she has judged to be clinically relevant.

\section{Acknowledgement}

The authors are thankful for the assistance rendered by the Health Records Department of the Ahmadu Bello University Teaching Hospital during the period of data collection.

\section{Disclosure}

No conflicts of interest declared concerning the publication of this article.

\section{References}

1. Murray CJL, Lopez AD. The global burden of disease. Cambridge: Harvard University Press; 1996.

2. Tandon R. Antipsychotics in the treatment of schizophrenia: an overview. J Clin Psychiatry. 2011;72:4-8.

3. Stroup TS. Pharmacotherapy for schizophrenia: Acute and maintenance phase treatment [Internet]. In: Stein MB, editor. UpToDate [cited 2015 June 5]. http//www.uptodate.com

4. Delay J, Deniker P. The treatment of psychosis by a method derived neurolytic the hibernotherapie: the 4560 RP used only in prolonged treatment continuation. Med Alien Neurol (France). 1952;50:497-502.

5. Laborit $H$, Huguenard $P$, Alluaume R. A new vegetative stabilizer (the 4560 RP). Presse Med. 1952;60:206-8.

6. Lieberman JA. Atypical antipsychotic drugs as a first-line treatment of schizophrenia: a rationale and hypothesis. J Clin Psychiatry. 1996;57:68-71.

7. Marston L, Nazareth I, Peterson I, Walters K, Osborn PJD. Prescribing of antipsychotics in UK primary care: a cohort study. BMJ Open. 2012;4:e006135.

8. Banergee I, Roy B, Sathian B, Banergee I, Chakraborty PK, Saha A. Sociodemographic profile of utilization pattern of antipsychotic drugs among schizophrenic inpatients: a cross sectional study from western region of Nepal. BMC Psychiatry. 2013;13:96.

9. Rode SB, Salankar HV, Pravin R. Verma PR, Sinha U, Ajagallay RK. Pharmacoepidemiological survey of schizophrenia in Central India. Int J Res Med Sci. 2014;2:1058-62.

10. Park SC, Lee MS, Kang SG, Lee SH. Pattern of antipsychotic prescription to patients with schizophrenia in Korea: results from the health insurance review \& assessment service-national patient sample. J Korean Med Sci. 2014;29:719-28.

11. Weinbrenner S, Assion HJ, Stargardt T, Busse R, Juckel G, Gericke CA. Drug Prescription Patterns in Schizophrenia Outpatients: Analysis of Data from a German Health Insurance Fund. Pharmacopsychiatry. 2008;41:1-6.

12. Si TM, Shu L, Li KQ, Liu XH, Mei QY, Wang GH. Factors that influence the prescription of antipsychotics for patients with schizophrenia in China. Clin Psychopharmacol Neurosci. 2011;9:122-8.

13. Famuyiwa OO. Psychotropic drug prescription in Nigeria. Acta Psychiatr Scand. 1983;68:73-81.

14. Igbinomwanhia NG, Olotu SO, James BO. Prevalence and correlates of antipsychotic polypharmacy among outpatients with schizophrenia attending a tertiary psychiatric facility in Nigeria. Ther Adv Psychopharmacol. 2017;7:3-10.

15. Kabir A, Muhammad AA, Jimoh AO, Abubakar SB. Prescription Pattern of Antipsychotic Drugs-A Case study of a Neuro-psychiatric 
Hospital in North-Western Nigeria. Eur J Sci Res. 2013;95:3327.

16. Adesola AO, Anozie IG, Erohibie P, James BO. Prevalence and correlates of "High dose" antipsychotic prescribing: findings from a hospital audit. Ann Med Health Sci Res. 2013;3:62-6.

17. Adamson TA. Prescribing habits for psychiatric in-patients admissions in a Nigerian psychiatric hospital. Afr J Med Sci. $1995 ; 24: 261-7$.

18. Chouniard G, Albright PS. Economic and health state utility determinations for schizophrenic patients treated with risperidone or haloperidol. J Clin Psychopharmacol. 1997;17:298-307.

19. Award AG, Voruganti LN. Impact of atypical antipsychotics in quality of life in patients with schizophrenia. CNS Drugs. 2004; 18:877-93.

20. Duarte M, Gonçalves F, Agostinho C, Lourenço B, Capeto I, Oliveira $\mathrm{J}$, et al. Patterns of antipsychotics prescription in a Psychiatric ward in Lisbon. A cross-sectional study. Eur Neuropsychopharmacol. 2015;25:S531.

21. Aleman A, Kahn RS, Selten JP. Sex differences in the risk of schizophrenia: evidence from meta-analysis. Arch Gen Psychiatry. 2003;60:565-71.

22. Gaite L, Vázquez-Barquero JL, Borra C, Ballesteros J, Schene A, Welcher B, et al. Quality of life in patients with schizophrenia in five European countries: the EPSILON study. Acta Psychiatr Scand. 2002;105:283-92.

23. Marwaha $S$, Johnson $S$, Bebbington $P$, Stafford $M$, Angermeyer MC, Brugha $T$ et al. Rates and correlates of employment in people with schizophrenia in the UK, France and Germany. $\mathrm{Br}$ J Psychiatry. 2007;191:30-7.

24. Edlinger $M$, Hofer $A$, Rettenbacher MA, Baumgartner $S$, Widschwendter CG, Kemmler G, et al. Factors influencing the choice of new generation antipsychotic medication in the treatment of patients with schizophrenia. Schizophr Res. 2009;113:246-51.

25. Jauhar S, Guloksuz S, Andlauer O, Lydall G, Marques JG, Mendonca $L$, et al. Choice of antipsychotic treatment by European psychiatry trainees: are decisions based on evidence? BMC Psychiatry. 2012;12:27.

26. Davis JM, Barter JT, Kane JM. Antipsychotic drugs. In: Kaplan HI, Sadock BJ, editors. Comprehensive textbook of psychiatry. Baltimore: Williams \& Wilkins; 1989 , vol. 5, p. 1591-626.

27. Baldessarini RJ, Cohen BM, Teicher M. Pharmacologic treatment. In: Levy ST, Ninan PT, editors. Schizophrenia: treatment of acute psychotic episodes. Washington: American Psychiatric Press; 1990. p. 61-118.

28. Dixon LB, Lehman AF, Levine J. Conventional antipsychotic medications for schizophrenia. Schizophr Bull. 1995;21:567-77.

29. Kane JM. Treatment of schizophrenia. Schizophr Bull. 1987; $13: 133-56$.

30. Verdoux $H$, Tournier $M$, Bégaud B. Anti-psychotic prescribing trends: a review of pharmaco epidemiological studies. Acta Psychiat Scand. 2010;121:4-10.

31. Lieberman JA, Stroup TS, McEvoy JP, Swartz MS, Rosenheck RA, Perkins DO, et al. Effectiveness of antipsychotic drugs in patients with chronic schizophrenia. N Engl J Med. 2005;353:1209-23.
32. Jones PB, Barnes TR, Davies L, Dunn G, Lloyd H, Hayhurst KP, et al. Randomized controlled trial of the effect on quality of life of second- vs first-generation antipsychotic drugs in schizophrenia: Cost Utility of the Latest Antipsychotic Drugs in Schizophrenia Study (CUtLASS 1). Arch Gen Psychiatry. 2006;63:1079-87.

33. Lewis SW, Davies L, Jones PB, Barnes TR, Murray RM, Kerwin R, et al. Randomised controlled trials of conventional antipsychotic versus new atypical drugs, and new atypical drugs versus clozapine, in people with schizophrenia responding poorly to, or intolerant of, current drug treatment. Health Technol Assess. 2006;10: iii-iv, ix-xi, 1-165.

34. Geddes J. Atypical antipsychotics in the treatment of schizophrenia: systematic overview and meta-regression analysis. BMJ. 2000;321:1371.

35. Bernheim SM, Ross JS, Krumholz HM, Bradley EH. Influence of patients' socioeconomic status on clinical management decisions: a qualitative study. Ann Fam Med. 2008;6:53-8.

36. Bebbington PE, Angermeyer M, Azorin JM, Marwaha S, Marteau F, Toumi M. Side effects of antipsychotics medication and healthrelated quality of life. Acta Psychiat Scand. 2009;119:22-8.

37. Tandon R, Jibson MD. Extrapyramidal side effects of antipsychotics treatment: scope of problem and impact on outcome. Ann Clin Psychiatry. 2002;14:123-9.

38. Marder SR, Essock SM, Miller AL, Buchanan RW, Davis JM, Kana JM et al. The mount Sanai conference on the pharmacology of Schizophrenia. Schizophr Bull. 2002;28:5-16.

39. Van Putten T. Why do schizophrenic patients refuse to take their drugs? Arch Gen Psychiatry. 1994;31:67-72.

40. Peluso MJ, Lewis SW, Barnes TRE, Jones PB. Extrapyramidal motor side-effects of first-and second-generation antipsychotics drugs. Br J Psychiatry. 2012;200:387-92.

41. Leslie DL, Mohamed S, Rosenheck RA. Off-label use of antipsychotic medications in the department of Veterans Affairs health care system. Psychiatr Serv. 2009;60:1175-81.

42. Bhana N, Foster RH, Olney R, Plosker GL. Olanzapine: an updated review of its use in the management of schizophrenia. Drugs. 2001;61:111-61.

43. Spielmans GI. The promotion of olanzapine in primary care: an examination of internal industry documents. Soc Sci Med. 2009:27:14-20.

44. Lehman FA, Lieberman, JA, Dixon LB, McGlashan TH, Miller AL, Perkins DO, et al. Practice guideline for the Treatment of patients with Schizophrenia, Second edition. Am J Psychiatry. 2004;161(2 Suppl.).

\section{Correspondence:}

Christopher I. Okpataku

Dept. of Psychiatry, College of Health Sciences, Bingham University/Bingham University Teaching Hospital

PMB 2238 - Jos, Nigeria

E-mail: zehi29@yahoo.com

Tel.: +2348069295928, +2348188960428 